\title{
Spatiotemporal patterns of the fish assemblages downstream of the Gezhouba Dam on the Yangtze River
}

\author{
TAO JiangPing ${ }^{1}$, GONG YuTian ${ }^{1}$, TAN XiChang ${ }^{2}$, YANG Zhi ${ }^{1} \&$ CHANG JianBo ${ }^{1 *}$ \\ ${ }^{1}$ Key Laboratory of Ministry of Water Resources for Ecological Impacts of Hydraulic-projects and Restoration of Aquatic Ecosystem, \\ Institute of Hydroecology, Ministry of Water Resources \& Chinese Academy of Sciences, Wuhan 430079, China; \\ ${ }^{2}$ Pearl River Fishery Research Institute, Chinese Academy of Fishery Sciences, Guangzhou 510380, China
}

Received January 12, 2012; accepted June 11, 2012

\begin{abstract}
An explicit demonstration of the changes in fish assemblages is required to reveal the influence of damming on fish species. However, information from which to draw general conclusions regarding changes in fish assemblages is insufficient because of the limitations of available approaches. We used a combination of acoustic surveys, gillnet sampling, and geostatistical simulations to document the spatiotemporal variations in the fish assemblages downstream of the Gezhouba Dam, before and after the third impoundment of Three Gorges Reservoir (TGR). To conduct a hydroacoustic identification of individual species, we matched the size distributions of the fishes captured by gillnet with those of the acoustic surveys. An optimum threshold of target strength of $-50 \mathrm{~dB}$ re $1 \mathrm{~m}^{2}$ was defined, and acoustic surveys were purposefully extended to the selected fish assemblages (i.e., endemic Coreius species) that was acquired by the size and species selectivity of the gillnet sampling. The relative proportion of fish species in acoustic surveys was allocated based on the composition (\%) of the harvest in the gillnet surveys. Geostatistical simulations were likewise used to generate spatial patterns of fish distribution, and to determine the absolute abundance of the selected fish assemblages. We observed both the species composition and the spatial distribution of the selected fish assemblages changed significantly after implementation of new flow regulation in the TGR, wherein an immediate sharp population decline in the Coreius occurred. Our results strongly suggested that the new flow regulation in the TGR impoundment adversely affected downstream fish species, particularly the endemic Coreius species. To determine the factors responsible for the decline, we associated the variation in the fish assemblage patterns with changes in the environment and determined that substrate erosion resulting from trapping practices in the TGR likely played a key role.
\end{abstract}

fisheries acoustics, geostatistics, fish assemblage, CPUE, impoundment of Three Gorges Reservoir, Yangtze River

Citation: $\quad$ Tao J P, Gong Y T, Tan X C, et al. Spatiotemporal patterns of the fish assemblages downstream of the Gezhouba Dam on the Yangtze River. Sci China Life Sci, 2012, 55: 626-636, doi: 10.1007/s11427-012-4349-0

One of the most serious effects of damming a river on fish species is the habitat fragmentation that results from the "barrier effect" [1]. The impacts are often reflected as changes in the spatial distribution of fish assemblages [2]. The Yangtze River has 378 fish species on record, including 162 that are endemic to the river [3]. Since the construction of two large Dams (Gezhouba Dam and Three Gorges Dam) on the Yangtze River, there have been significant negative

*Corresponding author (email: jbchang@mail.ihe.ac.cn) changes to fish populations [4].

Unfortunately, there is little empirical evidence to document the impact of these two large dams on fish species in the Yangtze. There have been some studies that aimed to address this issue based on either speculation (e.g., [4-7]) or model assumptions (e.g., [8,9]). Due to the limitations associated with the available approaches, data from previous studies are insufficient. Moreover, general conclusions regarding the transformation of fish assemblages cannot be obtained [10]. Thus, it is not currently possible to draw 
general conclusions regarding the impact of damming on the changes in fish assemblages.

The most frequently used approaches, whether catch statistics (i.e., trawl sampling and gillnet sampling) or acoustic surveys have advantages and disadvantages when used to obtain data on fish assemblage changes. Catch statistics provide information on species composition, size distribution, and weight at length that allows for relative abundance estimates (e.g., catch per unit effort (CPUE) [11] and maximum sustainable yield (MSY) [12]). However, catch statistics cannot overcome significant biases because of limitations in size and species selectivity [11-13]. Conversely, acoustic surveys offer an alternative technique for quantifying fish density, abundance, and size distribution that allows for absolute abundance estimates [14]. However, this type of approach is frequently limited in terms of species identification $[15,16]$ and by highly skewed distributions of fish density [17].

To overcome the limitations associated with acoustic surveys, echo signals in the echogram are proportionally allocated based on the species proportions of fish caught in stock assessments [14]. To make precise estimates of fish abundance, geostatistical methods have been combined with fisheries acoustics in recent years. Acoustic surveys provide a set of coherent tools that explicitly take autocorrelation into account [17-19] and fulfill the requirements of geostatistical simulations. Thus, instead of producing a single, average case estimate, geostatistical simulations provide several alternative realizations of the values of interest $[20,21]$. Geostatistical simulations also enable descriptions and quantifications of the distribution patterns of fish density over different scales of observation, as well as estimations of density precision while accounting for the effects of heterogeneous distribution [22].

In view of the above, we used a combination of acoustic surveys, gillnet surveys, and geostatistical simulations to determine the spatial distribution of fish assemblages downstream of the Gezhouba Dam during the impounding period of the Three Gorges Reservoir (TGR). The study area was purposefully selected for two reasons. First, the study area is a significant habitat for two endemic species: Coreius heterodon and Coreius guichenoti [23,24]. Second, the study area, which is $38 \mathrm{~km}$ downstream from the Three
Gorges Dam, is one of the most significantly influenced areas resulting from the TGR impoundment [25]. From the time the TGR began the third impoundment (i.e., $175 \mathrm{~m}$ experimental impoundment) in September 2008, the water level in the TGR was raised from 156 to $175 \mathrm{~m}$ [26]. The new regulations for water flow raised the water level by $\sim 20 \mathrm{~m}$ during the dry seasons, which may have affected numerous fish species [27,28].

Annual variations in the spatial patterns of the fish communities were determined by the following three steps. First, gillnet surveys were used to determine the species composition and dominant species, as well as to calculate gillnet CPUE. Second, because both gillnet sampling and acoustic surveys provide information on the fish size distribution $[13,14]$, the size distribution of fishes caught was associated with that of acoustic surveys. This step enabled the determination of the same boundary of fish size and overcame the limitation of the acoustic surveys in terms of species identification. From a statistical point of view, the contribution (\%) of a species to the total catch was used to allocate fish individuals in the acoustic surveys. Therefore, acoustic surveys were purposefully extended to the selected fish assemblages that were acquired based on the selectivity of the gillnet surveys. Third, geostatistical simulations were used to generate spatial patterns in fish density and the absolute abundance of dominant species.

\section{Methods}

\subsection{Data acquisition}

We conducted acoustic surveys and gillnet sampling downstream of the Gezhouba Dam on the Yangtze River between 2006 and 2009. The survey area, from the Grezhouba Dam to the Yanshou Islet, was $\sim 10 \mathrm{~km}$ in length with a surface area of $\sim 10 \mathrm{~km}^{2}$ (Figure 1). The river width ranged from 600 to $1700 \mathrm{~m}$, and the water depth ranged from 15 to $40 \mathrm{~m} \mathrm{[15].}$

Acoustic surveys were conducted using a SIMRAD EY60 echo sounder, the procedure for which is detailed elsewhere [15]. A description of the sampling data is given in Figure 1 and Table 1.

Daily gillnet sampling was conducted using local fishing

Table 1 Basic information on acoustic and gillnet surveys

\begin{tabular}{|c|c|c|c|c|c|}
\hline & & 2006 & 2007 & 2008 & 2009 \\
\hline \multirow{6}{*}{$\begin{array}{l}\text { Acoustic } \\
\text { surveys }\end{array}$} & Survey periods & 15 Nov-17 Nov & 22 Nov-25 Nov & 29 Nov -1 Dec & 18 Nov-20 Nov \\
\hline & Total sailed distance $(\mathrm{km})$ & 116.08 & 181.51 & 119.84 & 102.06 \\
\hline & Depths (m) (mean \pm SD) & $12.74 \pm 4.21$ & $12.66 \pm 5.39$ & $13.97 \pm 5.27$ & $11.65 \pm 4.94$ \\
\hline & Frequency $(\mathrm{kHz})$ & 200 & 200 & 120 & 120 \\
\hline & Operation Power (W) & 300 & 300 & 240 & 240 \\
\hline & Pulse length (ms) & 0.128 & 0.128 & 0.128 & 0.128 \\
\hline \multirow{2}{*}{$\begin{array}{c}\text { Gillnet } \\
\text { samplings }\end{array}$} & Sampling net $\cdot$ day & 65 & 54 & 47 & 42 \\
\hline & Total catches in individuals & 2207 & 1692 & 569 & 508 \\
\hline
\end{tabular}




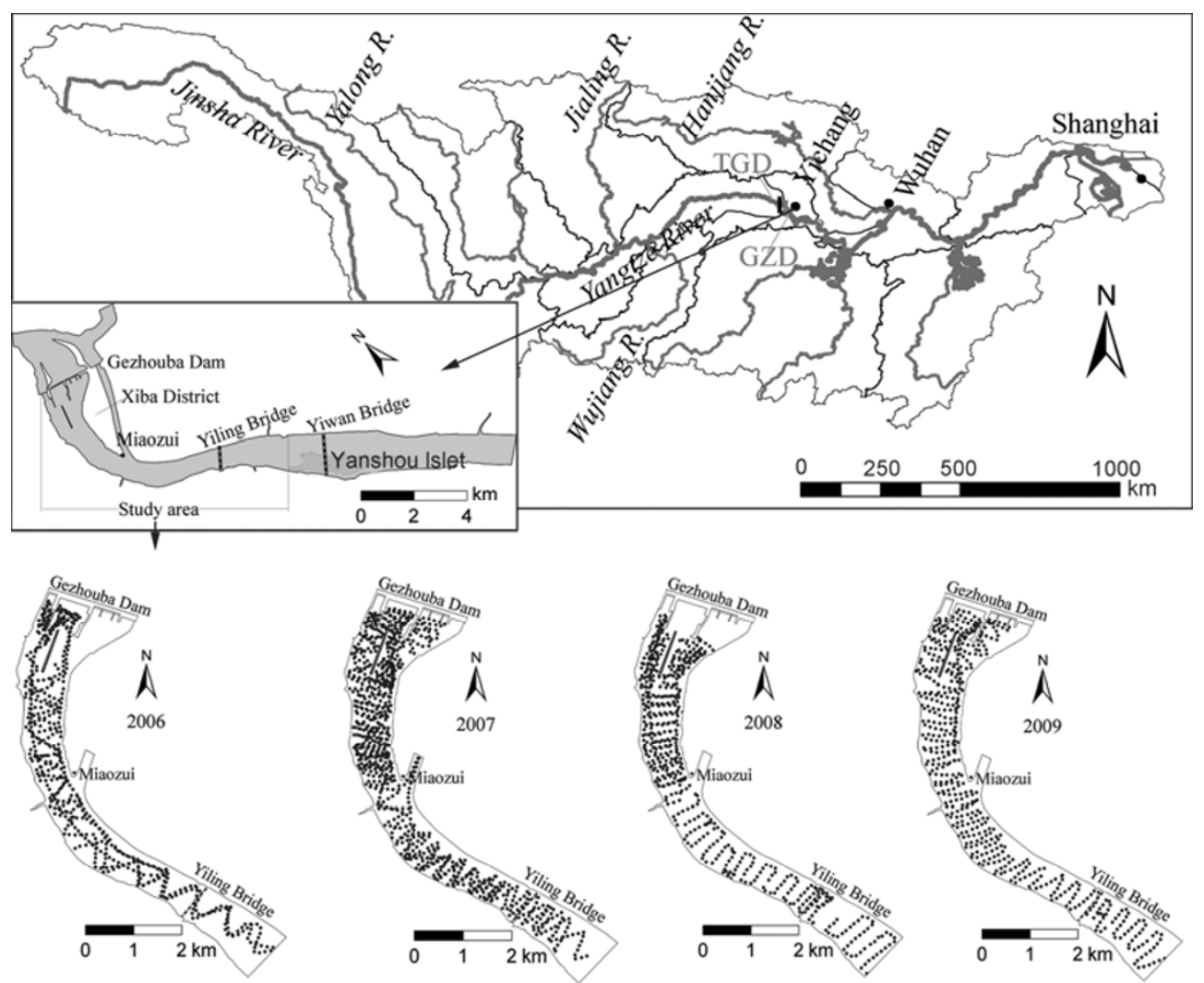

Figure 1 Map of the Yangtze River basin and study site showing the transects for the acoustic surveys. TGD, Three Gorges Dam; GZD, Gezhouba Dam.

boats from the Gezhouba Dam to the Yanshou Islet (Table $1)$. We used nylon gillnets ( $\sim 50 \mathrm{~m}$ long and $5 \mathrm{~m}$ wide) in three mesh sizes $(4,6$, and $8 \mathrm{~cm})$. The gillnets drifted with the current at the bottom and mid levels of the water column, which was consistent with the waters sampled by acoustic survey. The soak time of each net set ranged from 2-10 h $\mathrm{d}^{-1}$. We recorded the daily set duration, number of sets, and total catch for each net set. Following capture, all fish were identified, counted, measured $( \pm 1 \mathrm{~mm})$, and weighed $( \pm 1 \mathrm{~g})$.

\subsection{Acoustic data processing}

We used sonar 5 post-processing software (Ver. 5.9.8, Lindem Data Acquisition, Oslo) to process the acoustic data. In setting the parameters, we applied a time-varied gain of $40 \log R$ to compensate for the echo amplitudes of beam spreading and absorption. The remaining parameters were set to default [29].

We analyzed acoustic data within the range of $2 \mathrm{~m}$ from the transducer to $0.5 \mathrm{~m}$ above the bottom layer (i.e., the near-field and dead zones were excluded). We used the single echo detection and tracking method (STM) [29] to detect fish tracks to evaluate fish density at a threshold value $\left(-60 \mathrm{~dB}\right.$ re $\left.1 \mathrm{~m}^{2}\right)$, which was the lowest possible value that did not include too much noise in the echogram.

Because there is no target strength (TS)-fish length relationship available for Yangtze species, we used the empirical equation described by Love [30]. This equation enables the direct conversion of results obtained from different frequencies:

$$
\mathrm{TS}=19.1 \cdot \log (L)-0.9 \cdot \log (F)-62.0,
$$

where $L$ is the fish length in $\mathrm{cm}, F$ is the frequency in $\mathrm{kHz}$, and TS is the mean target strength of each fish track in $\mathrm{dB}$ re $1 \mathrm{~m}^{2}$. TS was calculated as [24]

$$
\mathrm{TS}=10 \cdot \log \left(\frac{1}{n} \sum_{i=1}^{n} \sigma_{b s(i)}\right),
$$

where $\sigma_{b s}$ is the backscattering coefficient of each echo and $n$ is the number of echoes in each track.

\subsection{Acoustic species identification and fish density de- termination}

To overcome the species identification limitation of acoustic surveys, we matched the size distribution of fish lengths for the fish caught by gillnet with that of the TS and acoustic fish length (converted from TS). The optimum threshold TS setting was further evaluated under conditions where the boundary and distribution patterns of the frequency distributions were similar, both in terms of the fish captured and TS. To ensure that the fish in both the acoustic and gillnet surveys were derived from the same population (i.e., the same fish assemblages and fish populations), we further examined the confidence levels of the matching using a $t$-test analysis. Thus, the relative proportion $(\%)$ of each species in the gill net surveys can be used to assign propor- 
tional representation of species in the acoustic data.

To determine the acoustic fish density, survey lines were divided into elementary distance sampling units (EDSU) of $\sim 180 \mathrm{~m}$, yielding 2837 acoustic data points. Considering that almost all targets appeared as single echoes on the echogram, the fish density (individuals per hectare, ind. $\mathrm{hm}^{-2}$ ) was calculated in each EDSU using the echo counting method [29,31].

\subsection{Geostatistical simulations}

We used ordinary kriging to simulate the spatial distribution of fish density. In comparison with other interpolation techniques, ordinary kriging has the distinguishing feature of being an unbiased simulation that is stable under different predictive conditions [32-34].

During analysis, the frequency distributions of fish density that departed significantly from the normality were subjected to natural logarithmic transformation $\operatorname{Ln}(X+1)$. Although normality is not a requirement for kriging, the procedure performs best when the distribution is close to normal [32].

The logarithmic fish densities were imported into a geographical information system (ArcGIS9.3, ESRI Corporation, Redlands, CA, USA) for simulations. The directions and nearest neighbors (lag sizes) of the autocorrelation were determined by directional distribution and average-nearestneighbor analysis in the spatial statistical analysis [33]. The lag sizes were divided into 10 groups for range prediction. To predict the density at unsampled locations, a maximum of five and a minimum of two neighbors were used in each sector along with the theoretical variogram.

The variogram used to examine the correlation among the grids was as follows [34]:

$$
\gamma(h)=\frac{1}{2|N(h)|} \sum_{N(h)}\left(\rho\left(s_{i}\right)-\rho\left(s_{j}\right)\right)^{2},
$$

where $\rho$ is an observation (e.g., density) referenced to its location $s_{i}=[$ latitude, longitude], lag $(h)$ is the distance vector separating the observations such that $s_{i}-s_{j}=h$, and $N(h)$ is the number of pairs of data locations that are a distance $(h)$ apart.

The spherical and exponential models were fitted to all empirical variograms using the weighted least-squares method [18]. Both asymptotic model fits yielded nugget $\left(C_{0}\right)$, partial sill $(C)$, sill $\left(C_{0}+C\right)$, and range $(a)$ estimates. The nugget describes the sampling error (uncertain variation) and/or microscale variation. The sill is the asymptote of the variogram that occurs within the predicted range (structural variation). The partial sill describes the spatial component of the semivariance $(\gamma)$ [32]. The ratio of the nugget to the sill $\left(C_{0} / C_{0}+C\right)$ indicates the degree of autocorrelation. Ratios of $<25 \%, 25 \%-75 \%$, and $>75 \%$ indicate strong, moderate, and weak spatial dependence, respectively $[35,36]$.

To obtain the optimum prediction, statistical errors such as the mean error (ME), root-mean-square error (RMS), and average standard error (ASE) were determined during the predictions [18]. The ME provides a measure of bias, whereas RMS and ASE provide measures of accuracy. When ME is close to zero, ASE is close to the RMS and the prediction variability is correctly assessed [37].

\subsection{Estimates of absolute abundance and catches per unit effort (CPUE)}

To obtain absolute abundance estimates, the vector maps produced by geostatistical simulations were transformed into grid maps with $10 \mathrm{~m}$ grids. The predicted values of the logarithmic fish density data were reverse transformed to the original units. The total fish abundance was calculated by summing the fish density over all grids by multiplying the area represented by each grid [21,32]. The abundance of dominant species was allocated proportionally based on the species proportions of the fishes caught in the gillnets.

To obtain CPUE estimates, the capture of all fish in the gillnets was standardized to a coherent duration of $3 \mathrm{~h}$. The standardized catch was defined as the daily catch and the CPUE was expressed as the number of fish caught per day (ind./net day).

Both endemic species $C$. heterodon and $C$. guichenoti belong to the genus Coreius, and share similar ecological characteristics $[3,38]$. Thus, the abundance and CPUE of both species were taken into account together.

\subsection{Descriptive statistics}

We used a Kolmogorov-Smirnov (K-S) test to evaluate the normality of the frequency distribution of fish density. We compared the difference in fish length between acoustic and gillnet surveys using a $t$-test. One-way ANOVA was used to compare annual differences in CPUEs. The significance level was set at $P<0.05$ for all analyses. All statistical analyses were performed using SPSS 13.0 software.

\section{Results}

\subsection{Species composition}

We collected a total of 4976 individuals representing 29, 23, 21, and 22 species from 2006 to 2009. Coreius (i.e., C. heterodon and $C$. guichenoti) and Pelteobagrus vachelli were the dominant species in terms of both number of individuals and weights. These three species shared a high proportion of between $71.65 \%$ and $88.19 \%$ of individuals in those years. Coreius shared a proportion of $78.31 \%-83.16 \%$ of individuals from 2006 to 2008. By 2009, the figure had declined to $54.79 \%$ (Figure 2).

\subsection{TS vs. fish length}

Figure 3 illustrates that there is a turning point at $-50 \mathrm{~dB}$ re 

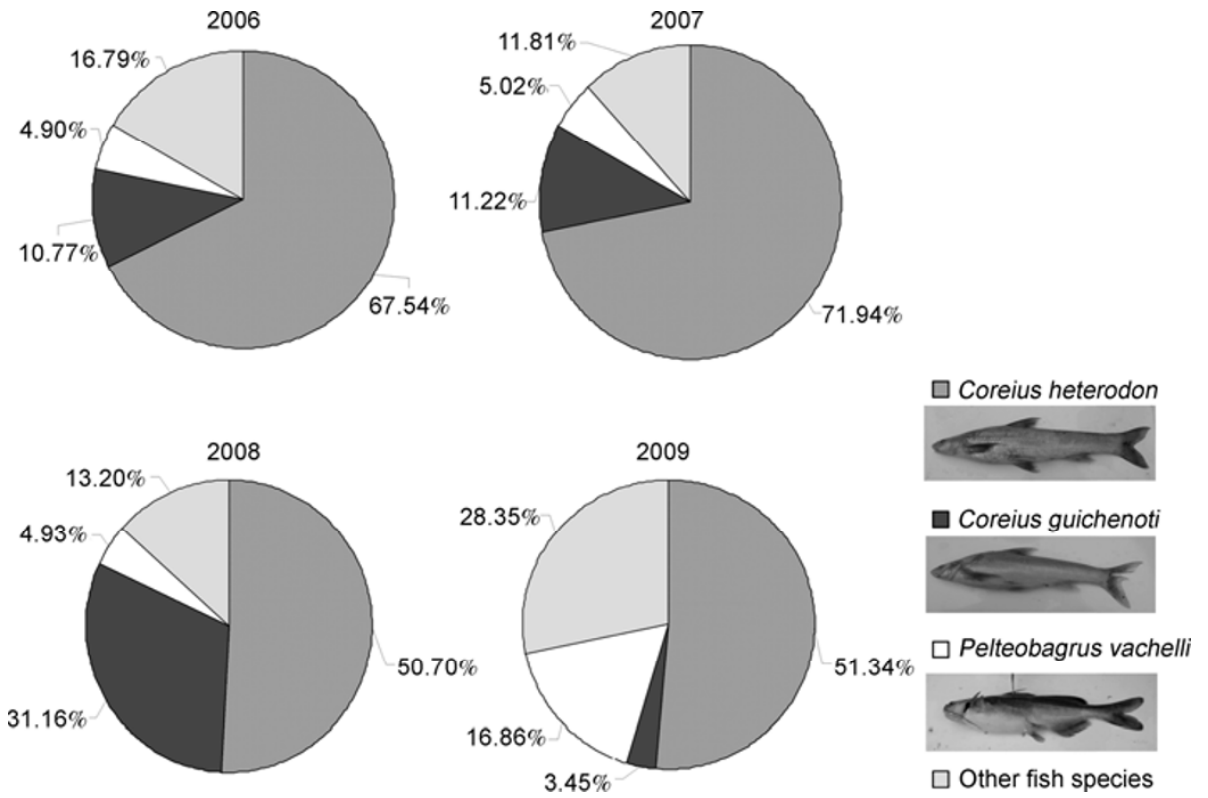

Figure 2 Composition of fish species captured by gillnet downstream of the Gezhouba Dam.
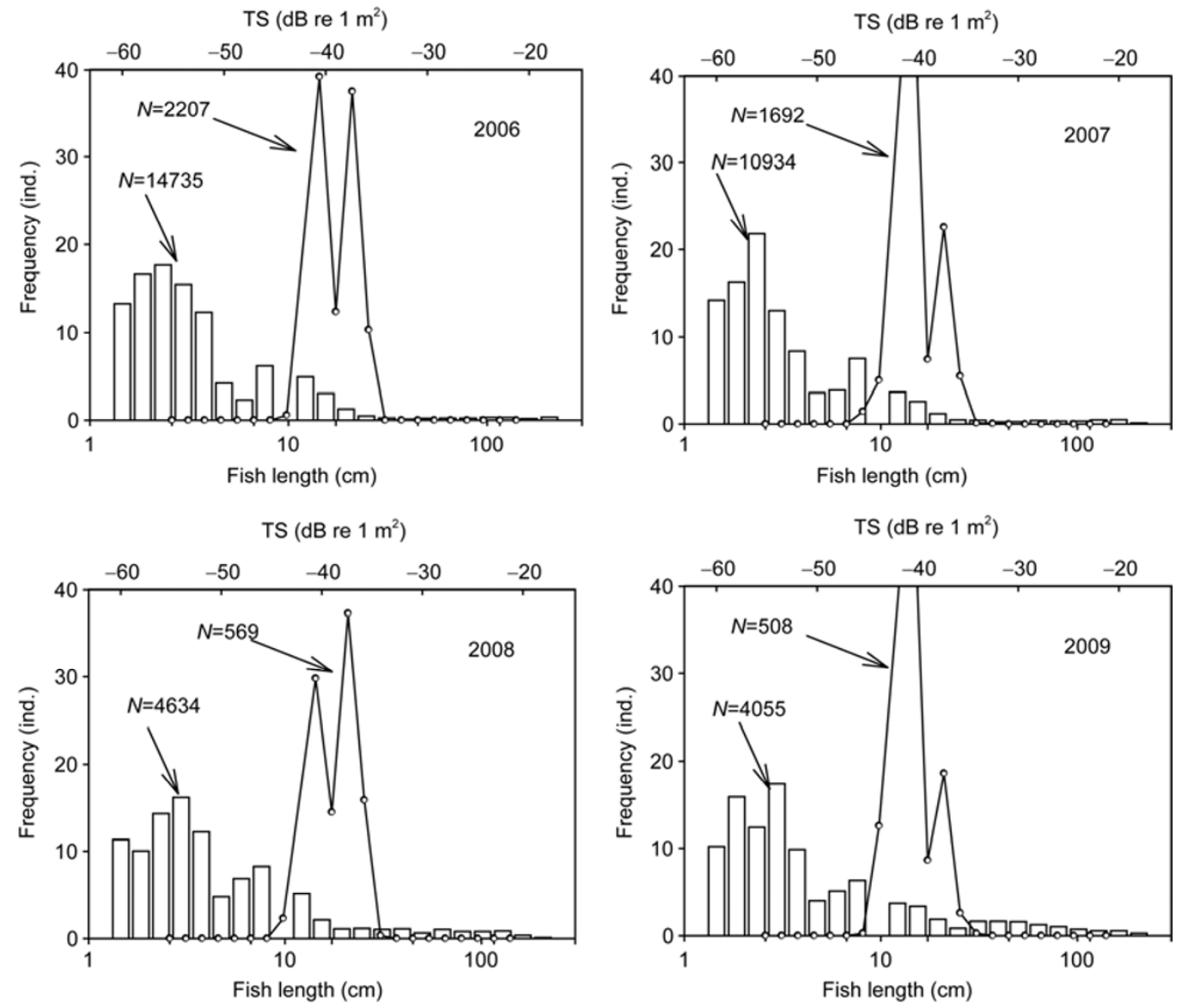

Figure 3 Size distribution of TS and fish length. Bar chart denotes the size distributions of TS with the corresponding acoustic fish length; linear graph denotes the size distributions of fishes captured by gillnet.

$1 \mathrm{~m}^{2}$ (i.e., acoustic fish length greater than $6 \mathrm{~cm}$ ). To a certain extent, the size distributions for TS and the acoustic fish length can be separated into two approximately normal distributions. The approximately normal distribution of TS 
and the acoustic fish length matched very well with those of fishes caught at a possible TS threshold of $-50 \mathrm{~dB}$ re $1 \mathrm{~m}^{2}$.

A small number of echoes with $\mathrm{TS}$ values greater than $-20 \mathrm{~dB}$ re $1 \mathrm{~m}^{2}$ were excluded from the following analysis because the corresponding fish length of such echoes exceeded $200 \mathrm{~cm}$, which was significantly than the maximum fish length of the selected fish assemblage.

At a TS threshold of $-50 \mathrm{~dB}$ re $1 \mathrm{~m}^{2}$, there was no significant difference in fish length between the gillnet catches and acoustic surveys from 2007 to 2009 (Figure 4), suggesting that sampling fish of both methods were derived from the same population. Thus, the contribution of a species to total catch can be used to account for the proportional representation of species in acoustic data. However, Figure 4 also illustrates a slight disparity in both fish lengths in 2006, as detailed in the Discussion section.

In the following spatial distribution and abundance estimates, the TS threshold was set at $-50 \mathrm{~dB}$ re $1 \mathrm{~m}^{2}$.

\subsection{Realizations of fish spatial distribution}

The frequency distributions of fish density departed significantly from normality, as characterized by the high number of zero values and only a few large values. The data were subjected to natural logarithmic transformation $\operatorname{Ln}(X+1)$, which resulted in a distribution close to normal (Table 2).

In the geostatistical simulations, 2387 grids $(\sim 180 \mathrm{~m}$ averages) of logarithmic fish density were used within the

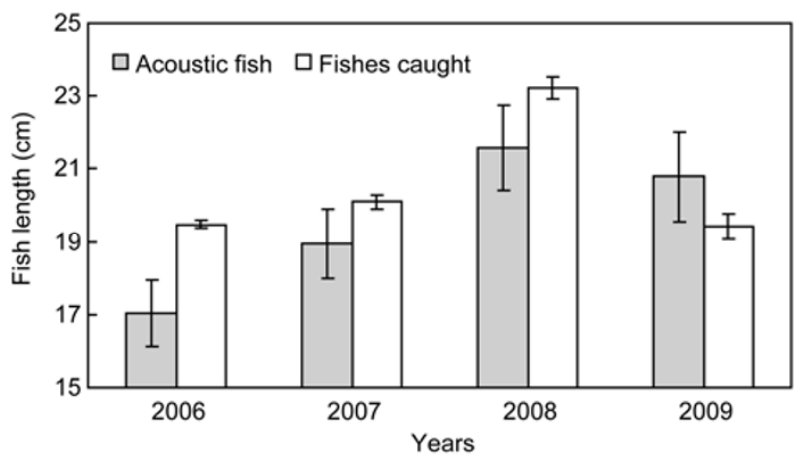

Figure 4 Comparison of the mean values of acoustic fish length and gillnet fish length at the TS threshold of $-50 \mathrm{~dB}$ re $1 \mathrm{~m}^{2}$ (mean $\pm \mathrm{SE}$ ). Acoustic fish denotes the fish length converted from the TS of each fish track. Fishes caught denote the fish length acquired by gillnet sampling. There was no difference in both measures of fish length from 2007 to 2009: $F=1.605, P=0.197$ (2007); $F=3.658, P=0.058$ (2008); $F=2.053, P=0.207$ (2009). A significant difference was observed in 2006, $F=7.532, P=0.000$. domain selected for analysis. For the parameters of the theoretical models, the ranges for four years of surveys varied from 52.27 to $81.84 \mathrm{~m}$. All these ranges did not exceed more than half of the maximum distance $(\sim 180 \mathrm{~m})$ of the two stochastic sampling points. A moderate degree of autocorrelation was observed in the spherical models because the nugget was $25.46 \%-65.22 \%$ of the sill. A higher degree of autocorrelation was observed in the exponential models because the nugget was $25.46 \%-55.02 \%$ of the sill, which was smaller than that of the exponential models (Table 3).

For statistical errors, all MEs in the exponential models were closer to zero than those in the spherical models, as expected for data in 2008. The RMS was closer to the ASE in the exponential models than in the spherical models. Thus, the exponential models better fitted the theoretical variograms in the surveys (Table 3 ).

Figure 5 illustrates that the theoretical variograms in the exponential models were regular and well behaved. The variograms converged on a sill in all cases, providing support for the assumption of stationarity. The structural spatial heterogeneity shared a proportion of $44.98 \%-74.54 \%$ (Table 3, Figure 5).

Figure 6 illustrates that the fish were frequently distributed in patch patterns. In the E-W direction (water flow direction), the fish density was higher on the left bank than on the right bank. In the N-S direction, the fish density was higher in the region from the Gezhouba Dam to the Yiling Bridge than in the area downstream of the Yiling Bridge. The patch sizes greater than 100 ind. $\mathrm{hm}^{-2}$ (i.e., FD>4.5 in Figure 6) accounted for a proportion of $18.23 \%, 23.75 \%$, $12.36 \%$, and $9.15 \%$ in the fish density from 2006 to 2009 , respectively.

The spatial patterns of fish distribution were similar between 2006 and 2007 because discrete patches were present in certain regions, such as downstream of the flushing sluice, near the dockyard and Miaozui sections, as well as the neighboring Zhengjiang tower area. The spatial patterns differed in 2008 because the patches of high fish density significantly decreased. By 2009, the spatial patterns varied significantly because of a decrease in patches of high fish density and regional changes in fish distribution (Figure 6).

\subsection{Acoustic fish abundance vs. CPUE}

A total of $56474,68848,35104$, and 37526 individuals in

Table 2 Descriptive statistics of the acoustic fish density (ind. $\mathrm{hm}^{-2}$ ) during the surveys ${ }^{\mathrm{a})}$

\begin{tabular}{ccccccccccccccc}
\hline Years & Mean & Median & Max. & SD & $\% 0$ & $\% \mathrm{CV}$ & $D$ & $P$ \\
\hline 2006 & 112.13 & 23.56 & 4239.10 & 362.58 & 40.16 & 323.57 & 9.51 & 0.000 & 2.59 & 0.000 & 628 \\
2007 & 104.94 & 33.56 & 4238.72 & 245.13 & 37.90 & 233.59 & 10.57 & 0.000 & 2.76 & 0.000 & 999 \\
2008 & 45.79 & 9.46 & 943.79 & 86.23 & 46.29 & 188.32 & 7.65 & 0.000 & 2.12 & 0.000 & 660 \\
2009 & 39.57 & 6.13 & 1034.28 & 142.22 & 54.25 & 359.41 & 9.16 & 0.000 & 2.97 & 0.000 & 550 \\
\hline
\end{tabular}

a) SD, Standard deviation; max., maximum; \%0, percentage of zeros; $\mathrm{CV}$, coefficient of variation; $n$, number of samples; $D$ and $P$, K-S test for normality of original values; $D_{\mathrm{L}}$ and $P_{\mathrm{L}}, \mathrm{K}-\mathrm{S}$ test for normality of logarithmic values. All the minimum values (zero) are not tabulated. 
Table 3 Exponential (Exp) and spherical (Sph) models fitted the theoretical variograms and statistical errors from the interpolation of fits ${ }^{\text {a) }}$

\begin{tabular}{ccccccccc}
\hline \multirow{2}{*}{ Years } & \multicolumn{3}{c}{ Parameters of theoretical models } & \multicolumn{3}{c}{ Statistical errors } \\
\cline { 2 - 9 } & Model & $C_{0}$ & $C$ & $\% C_{0} /\left(C_{0}+C\right)$ & $A$ & ME & RMS & ASE \\
\hline \multirow{2}{*}{2006} & Sph & 1.50 & 4.39 & 25.46 & 54.58 & 0.005 & 1.845 & 1.866 \\
& Exp & 1.50 & 4.39 & 25.46 & 54.58 & 0.005 & 1.814 & 1.816 \\
2007 & Sph & 3.30 & 1.76 & 65.22 & 81.47 & -0.006 & 2.137 & 2.199 \\
& Exp & 3.12 & 2.55 & 55.02 & 63.48 & -0.006 & 2.136 & 2.105 \\
2008 & Sph & 1.63 & 2.97 & 35.43 & 50.48 & 0.001 & 1.693 & 1.585 \\
& Exp & 1.63 & 2.97 & 35.43 & 50.48 & 0.002 & 1.697 & 1.676 \\
& Sph & 6.21 & 4.48 & 58.09 & 58.87 & 0.004 & 1.968 & 2.013 \\
& Exp & 5.83 & 5.91 & 49.68 & 52.27 & -0.001 & 1.973 & 2.011 \\
\hline
\end{tabular}

a) $C_{0}$, nugget; $C$, partial sill; $A$, range (m); ME, mean error; RMS, root mean square error; ASE, the average standard error. Values for the sill, equal to the nugget plus the partial sill, are not tabulated.

the selected fish assemblages were acquired in the 81566 grids from 2006 to 2009. Figure 7 shows the variation in absolute abundance and CPUE with a corresponding $95 \%$ $\mathrm{CI}$ of the dominant species.

A declining tendency in both absolute abundance and CUPE for the Coreius population was observed since 2008. The absolute abundance declined by $\sim 50 \%$ and the decline in CPUE was significant (Figure 7A).

For $C$. guichenoti, both absolute abundance and CUPE fluctuated during the study period, with the lowest values occurring in 2008. The range of the fluctuation in absolute abundance was greater than that in the CPUE (Figure 7B).

\section{Discussion}

\subsection{Accuracy of data}

The hydroacoustic identification of individual species is at an early stage of development and is limited by serious physical uncertainties $[15,16]$. We used the contribution $(\%)$ of a species to the total catch in gillnet surveys to allocate the relative proportion of species in the acoustic surveys, as described previously $[39,40]$. However, the distribution of fish length in the acoustic surveys disagreed with that of the fish caught at the lowest possible TS threshold $(-60 \mathrm{~dB}$ re 1 $\mathrm{m}^{2}$ ) (Figure 3). Approximately 60 fish species inhabited the surveyed area $[3,38]$ and there was significant variation at the levels of the water column and size distribution among the species $[3,38,41]$. Using the acoustic surveys we conducted an unbiased survey of all species in the study area. However, because of biases associated with size, species, and size selectivity [11-13], the gillnet surveys targeted a more narrow range of species and fish sizes. Given this, the use of acoustic surveys to obtain fish abundance and spatial distribution data relies on pairing the coverage of acoustic surveys and direct sampling. We noted a turning point in the size distribution of $\mathrm{TS}$ at $-50 \mathrm{~dB} \mathrm{re}^{2}$, wherein the fre-
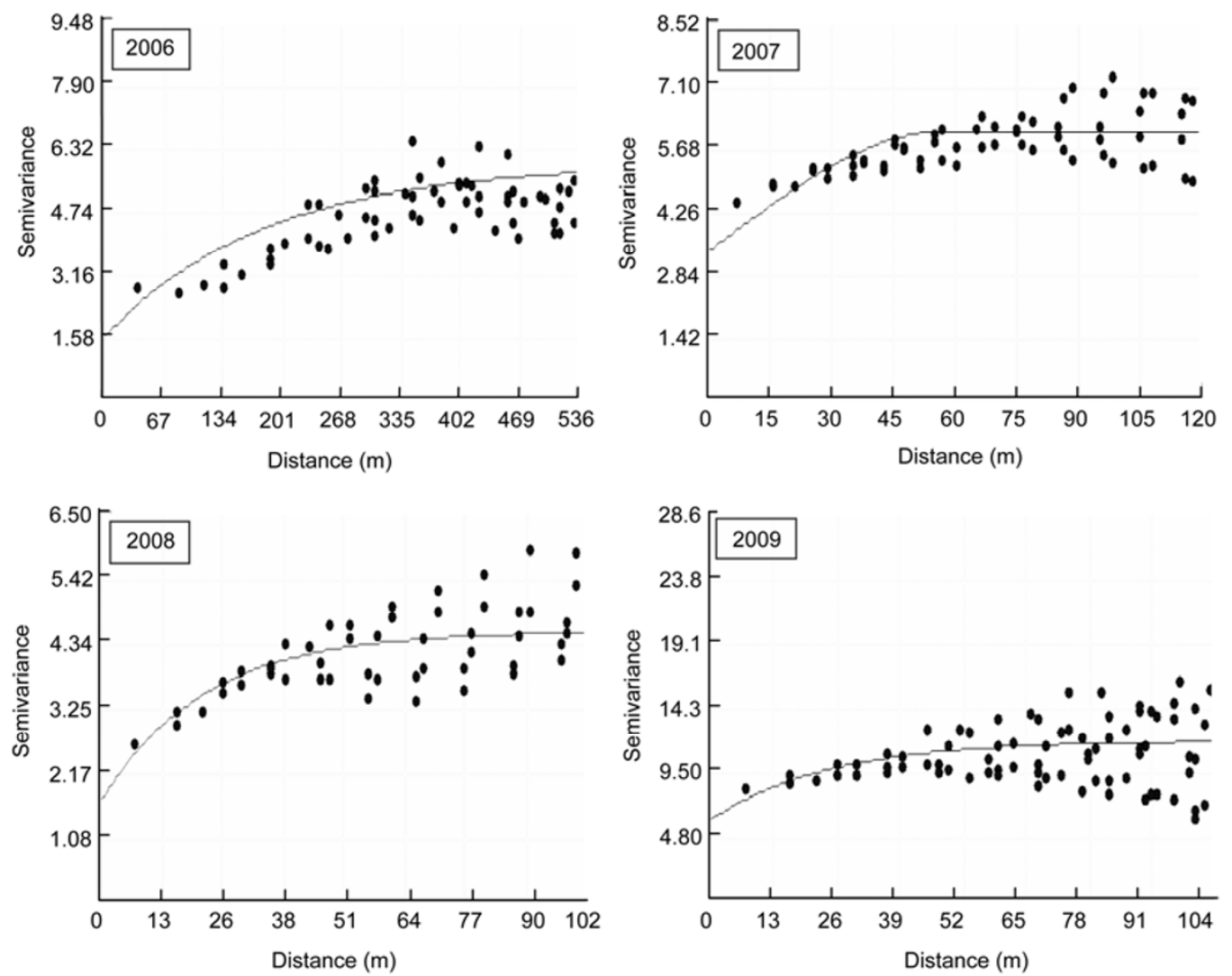

Figure 5 Theoretical variograms (points) and models (lines), showing the semivariance $(\gamma(h))$ as a function of lag distance for fish density. 

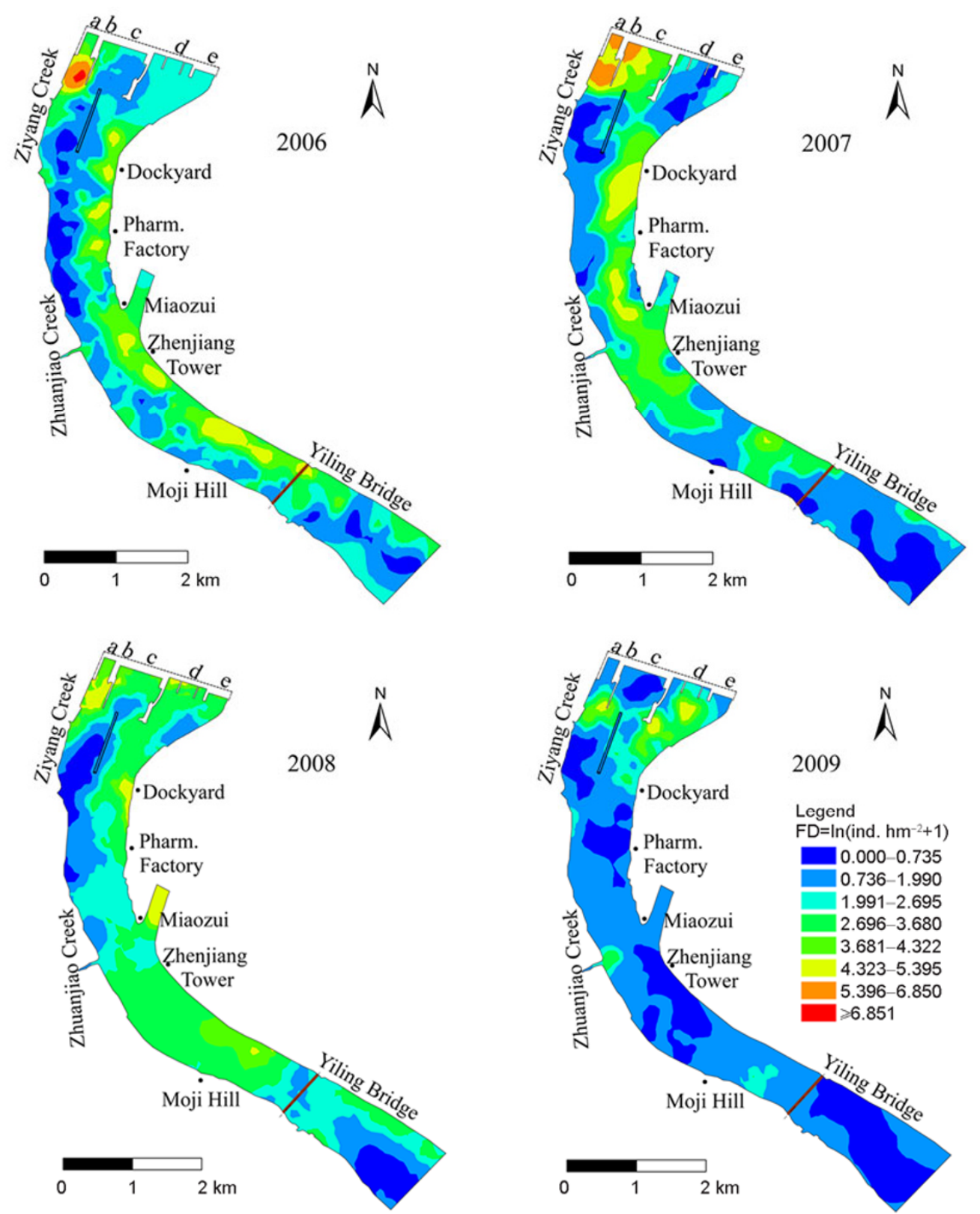

Figure 6 Spatial distribution of fish acquired by the interpolation of ordinary kriging (a, flushing sluice; b, ship lock, c, Dajiang Power Plant; d, Erjiang Power Plant; e, Erjiang sluice). The spatial distributions of fish density were unified in the same legend showing the annual changes in the patches.

quency distribution of fish length between the gillnet and acoustic surveys was similar (Figure 3).

Interestingly, at a TS threshold of $-50 \mathrm{~dB}$ re $1 \mathrm{~m}^{2}$, there was a significant disparity in the fish length between acoustic fish and fish caught in 2006 (Figure 4). The acoustic fish lengths were smaller than those in the gillnet, although the frequency distribution was similar (Figures 3 and 4). The disparity was likely caused by the absence of a TS-fish length relationship for Yangtze fish species, meaning the conversion was conducted using an empirical equation. As a result, the biases inevitably resulted in a disparity between the TS conversion and fish length [14-16]. Nevertheless, the match between the acoustic surveys and gillnet sam- plings for 2006 was justifiable because there was a high coherence among size distributions (Figure 3).

For geostatistical simulations, many zero values in the data sets are likely to cause a bias in the nugget effect upwards, ultimately leading to a biased estimation of data values [21]. In our simulations, the departure of the frequency distribution of fish density from normality was characterized by a high number of zero values $(37.90 \%-$ $54.25 \%$; Table 2). The nugget shared a high portion of sill (Table 3, Figure 5), which led to considerable spatial heterogeneity $(\sim 25.46 \%-55.02 \%)$ caused by uncertain variation, and possibly by sampling error [32]. Unfortunately, there are few effective means for overcoming this issue. A few 

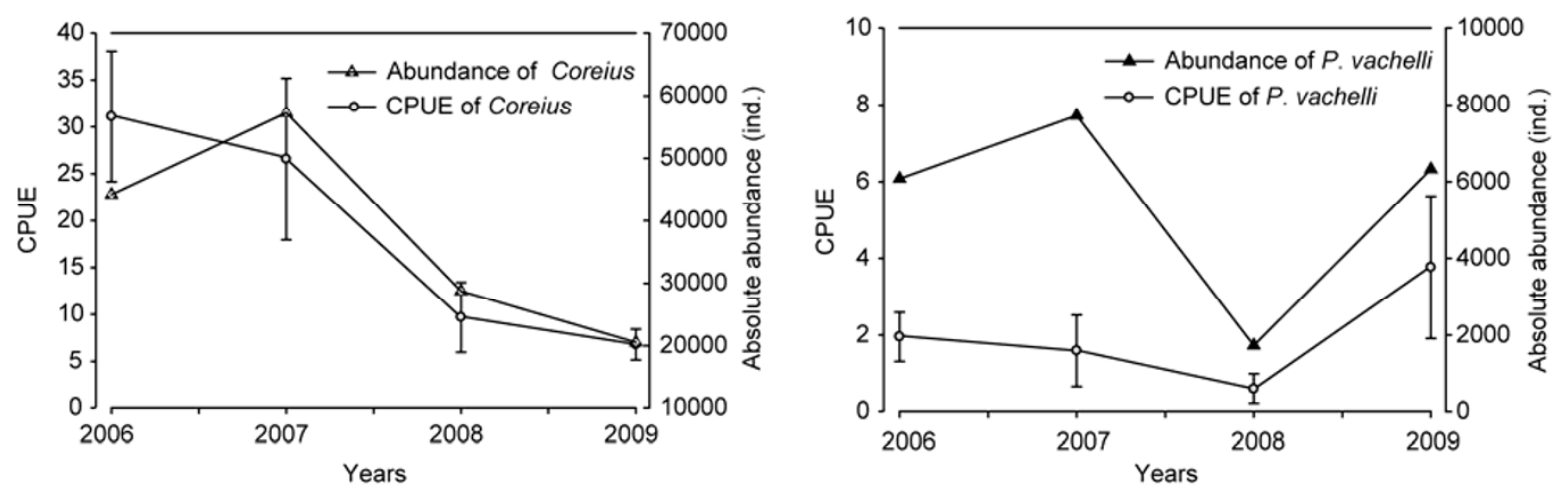

Figure 7 Variation in absolute fish abundance and 95\% CI of CPUE. For the CPUEs of Coreius, there was no significant change between 2006 and 2007 $(F=4.534 ; P=0.295)$ and between 2008 and $2009(F=2.90 ; P=0.563)$. There was a significant decline between 2007 and $2008(F=19.794 ; P=0.00)$. For the CPUEs of $C$. guichenoti, there was no significant change between 2006 and $2008(P>0.05)$. There was a significant increase in 2009 compared with the three remaining years $(F=1.809, P=0.025 ; F=2.171, P=0.010 ; F=3.167, P=0.000)$.

studies have attempted to treat such uncertainties through various means $[21,32,36,37]$, which generally result in new uncertainties. Thus, the process being followed is not completely clear [22].

As a result, we did not treat for uncertain variation in the current study. We believe the geostatistical simulations sufficiently represented the actual spatial pattern of fish distribution because we had only moderate autocorrelation and the statistical errors were close to zero (Table 3). Similarly, the errors of the subsequent absolute abundance estimates were ascertainable and explainable when compared with the CUPE and the descriptive statistics of fish density.

\subsection{Variations in the fish assemblages}

We observed a significant change in the fish assemblage since 2008 characterized by a change in species composition (Figure 2) and a sharp decline in the fish population, particularly in Coreius, in terms of CPUE and absolute abundance (Figure 7). Similarly, the spatial distribution of fish has changed considerably since 2009 (Figure 6).

Factors such as overfishing, pollution, and habitat fragmentation from dams are repeatedly reported as the causes of sharp declines in fish populations [27]. The decline in Coreius populations was associated with the timing of the third impoundment of the TGR in 2008. The same phenomenon was also observed during the first impoundment of the TGR in 2003, wherein a sharp decline occurred in the CPUEs of C. guichenoti [41]. Other studies indicate that changes in hydrological patterns associated with new flow regulation, particularly for short-term new flow fluctuations [42], have immediate effects on the integrity of river ecosystems and result in the loss or decline of numerous fish species [28]. The new flow regulation of the third TGR impounding may change hydrological patterns downstream of the Gezhouba Dam on the Yangtze River, and this change negatively affects the fish species.

However, a new flow regulation does not result in direct population decline because this type of influence on the fish population gradually occurs over several generations rather than immediately [43]. Instead, the change in flow regulation alters the hydrological patterns, which most probably resulted in habitat quality changes for endemic fish species [43-45]. Hence, endemic species moved away from the original habitat in response to changes in the habitat.

Our observations suggest that changes in species composition and the spatial distribution of fish were possibly caused by the decline in Coreius and the fluctuation in $C$. guichenoti abundance. The proportion of Coreius in the catch declined to $54 \%$ from $~ 80 \%$ (Figure 2). Because of the habitat selectivity of different species [44,45], significant changes in species compositions resulted in the spatial variability of fish distribution (Figure 6).

\subsection{Changes in environmental factors}

The influences of river damming on fish assemblages are complex and varied. Changes in the flow regulation [28,42], flow regime $[45,46]$, as well as physical and chemical characteristics $[10,47]$ potentially impose immediate adverse effects on downstream fish species.

However, because of the drought in 2006 and the floods upstream of the Yangtze River in 2008 [26], the downstream discharge in 2008 was significantly higher than in 2007 ( $P=0.030)$, and extremely significantly higher than in 2006 and $2009(P=0.000)$. There was no significant difference in discharge prior to flow regulation in 2006 and after the flow regulation in $2009(P=0.313)$. In addition, There was no significant difference in the daily variation in discharge $(P=0.053)$ (Hydrology of Yangtze: http://www.cjh. com.cn/, available Sept. 2011). There is currently no direct evidence that flow regulation through the third TGR impoundment is linked with variation in fish assemblages. Furthermore, the targeted monitor report [26] also noted there was no significant change in water quality during this impoundment. 
Because of entrapment by the TGD $[25,26]$, the sediment discharges delivered to the lower reach of the Gezhouba Dam during the third impoundment have declined by $45.55 \%$ compared with that in the period of the first and second impoundments. This figure declined by $99.34 \%$ compared with that before the TGR impoundment [26]. Our observations suggest there is a strong association between the variation in fish assemblages and the substrate erosion caused by the TGR impoundment. Although the substrate requirements for Coreius, and even for other Yangtze fishes, have not yet been studied, other studies have shown that habitat changes caused by substrate transformations severely affect fish species, both directly and indirectly [48]. Following construction of the TGD, the river channel in the mid-lower reaches has changed from a depositional to erosional state since 2002 [26].

In conclusion, we documented annual spatiotemporal variation in selected fish assemblages before and after the third TGR impoundment. Spatiotemporal variation in the structure of the selected fish assemblage was strongly associated with substrate erosion caused by the TGR impoundment. Despite the high correlation, determination of the certainty and the degree require further study. We also documented the spatiotemporal variation in fish assemblages under varying environmental conditions. Based on a combination of changes in habitat variables and the habitat heterogeneity of fish assemblages, the environmental requirements for fish species may be quantified in future studies. Knowledge of the environmental requirements of fish species is critical to managing ecological-base flow regulation in the TGR, and furthering the ecological restoration of aquatic resources on the Yangtze River.

We thank the staff of our research group, namely Wan Li, Cai YuPeng, Xu Wei, and Gong Yun for their help in fish collection and identification in the field surveys. This work was supported by the National Natural Science Foundation of China (Grant No. 51079089), Key Project of the National Twelfth-Five Year Research Program of China (Grant No. 2012BAC06B04), and the Ecological and Environmental Monitoring Programs of China Three Gorges Project Corporation (Grant Nos. 241202004 and SXSN/2726).

1 Morita K, Yamamoto S. Effects of habitat fragmentation by damming on the persistence of stream-dwelling Charr populations. Conserv Biol, 2002, 16: 1318-1323

2 Gillette D P, Tiemann J S, Edds D R, et al. Spatiotemporal patterns of fish assemblage structure in a river impounded by low-head Dams. Copeia, 2005, 3: 539-549

3 Zhu S Q, ed. Synopsis of Freshwater Fishes of China (in Chinese). Nanjing: Jiangsu Science and Technology Publishing House, 1995

$4 \mathrm{Fu} \mathrm{C}, \mathrm{Wu}$ J, Chen J, et al. Freshwater fish biodiversity in the Yangtze River basin of China: patterns, threats and conservation. Biodivers Conserv, 2003, 12: 1649-1685

5 Xie P. Three-gorges dam: risk to ancient fish. Science, 2003, 302: 1149

6 Wu J, Huang J, Han X, et al. The Three Gorges Dam: an ecological perspective. Front Ecol Environ, 2004, 2: 241-248

7 Stone R. Last stand on the Yangtze. Science, 2010, 329: 378

8 Park Y S, Chang J, Lek S, et al. Conservation strategies for endemic fish species threatened by the Three Gorges Dam. Conserv Boil, 2003, 17: $1748-1758$

9 Gao X, Brosse S, Chen Y, et al. Effects of damming on population sustainability of Chinese sturgeon, Acipenser sinensis: evaluation of optimal conservation measures. Environ Biol Fish, 2009, 86: 325336

10 De Mérona B, Albert P. Ecological monitoring of fish assemblages downstream of a hydroelectric dam in French Guiana (South America). Regul Rivers: Res Mgmt, 1999, 15: 339-351

11 Richards L J, Schnute J T. An experimental and statistical approach to the question: Is CPUE an index of abundance? Can J Fish Aquat Sci, 1986, 43: 1214-1227

12 Jørgensen C, Enberg K, Dunlop E S, et al. Managing evolving fish stocks. Science, 2007, 318: 1247-1248

13 Jurvelius J, Kolari I, Leskelä A. Quality and status of fish stocks in lakes: gillnetting, seining, trawling and hydroacoustics as sampling methods. Hydrobiol, 2011, 660: 29-36

14 Simmonds E J, MacLennan D N. Fisheries Acoustics: Theory and Practice. 2nd ed. Oxford: Blackwell Publishing, 2005

15 Tao J P, Qiao Y, Tan X C, et al. Species identification of Chinese sturgeon using acoustic descriptors and ascertaining their spatial distribution in the spawning ground of Gezhouba Dam. Chin Sci Bull, 2009, 54: 3972-3980

16 Kubecka J, Hohausová E, Matěna J, et al. The true picture of a lake or reservoir fish stock: A review of needs and progress. Fish Res, 2009, 96: 1-5

17 Petitgas P. Geostatistics for fish stock assessments: a review and an acoustic application. ICES J Mar Sci, 1993, 50: 285-298

18 Rivoirard J, Simmonds E J, Foote K G, et al. Geostatistics for Estimating Fish Abundance. Oxford: Blackwell Science, 2000

19 Petitgas P. Geostatistics in fisheries survey design and stock assessment: models, variances and applications. Fish Fish, 2001, 2: 231-249

20 Goovaerts P. Geostatistics for natural resources evaluation. Oxford: Oxford University Press, 1997

21 Gimona A, Fernandes P G. A conditional simulation of acoustic survey data: advantages and potential pitfalls. Aquat Living Resour, 2003, 16: 123-129

22 Mello L G S, Rose G A. Using geostatistics to quantify seasonal distribution and aggregation patterns of fishes: an example of Atlantic cod (Gadus morhua). Can J Fish Aquat Sci, 2005, 62: 659-670

23 Liu L H, Wu G X, Wang Z L, et al. Reproduction ecology of Coreius heterodon (bleeker) and coreius guichenoti (sauvage et dabry) in the mainstream of the Yangtze River after the construction of Gehouba Dam (in Chinese). Acta Hydrobiol Sinica, 1990, 14: 205-215

24 Tao J, Gao Y, Qiao Y, et al. Hydroacoustic observation of fish behavior and spatial patterns in the ship lock and adjacent areas of the Gezhouba Dam, Yangtze River. Acta Ecol Sinica, 2010, 30: 233-239

$25 \mathrm{Xu} \mathrm{K}$, Milliman J D. Seasonal variations of sediment discharge from the Yangtze River before and after impoundment of the Three Gorges Dam. Geomorphology, 2009, 104: 276-283

26 Changjiang Water Resources Commission. Technical report of $175 \mathrm{~m}$ experimental impoundment of Three Gorges Reservoir (in Chinese). CWRC, Wuhan, 2011

27 Dudgeon D. Large-scale hydrological changes in tropical Asia: prospects for riverine biodiversity. BioScience, 2000, 50: 793-806

28 Dudley R K, Platania S P. Flow regulation and fragmentation imperil pelagic-spawning riverine fishes. Ecol Appl, 2007, 17: 20742086

29 Balk H, Lindem T. Sonar4, Sonar5, Sonar6-Pro Post-processing Systems Manual version 5.98. University of Oslo, 2005

30 Love R H. Dorsal-aspect target strength of an individual fish. J Acoust Soc Am, 1971, 49: 816-823

31 Kieser R, Mulligan T J. Analysis of echo counting data: A model. Can J Fish Aquat Sci, 1984, 41: 451-458

32 Adams C F, Harris B P, Stokesbury K D E. Geostatistical comparison of two independent video surveys of sea scallop abundance in the Elephant Trunk Closed Area, USA. ICES J Mar Sci, 2008, 65: 995-1003 
33 Johnston K, VerHoef J M, Krivoruchko K, et al. Using ArcGIS Geostatistical Analyst. Redlands, ESRI, 2001. http://dusk.geo.orst.edu/ gis/geostat_analyst.pdf

34 Parker-Stetter S L, Rudstam LG, Sullivan P J, et al. Standard Operating Procedures for Fisheries Acoustic Surveys in the Great Lakes. Great Lakes Fish. Committee Specification Published. 09-01, 2009. http://www.glfc.org/pubs/SpecialPubs/Sp09_1.pdf

35 Cambardella C A, Moorman T B, Novak J M, et al. Field-scale variability of soil properties in central lowa soils. Soil Sci Soc Am J, 1994, 58: 1501-1511

36 Walline P D. Geostatistical simulations of eastern Bering Sea walleye pollock spatial distributions, to estimate sampling precision. ICES J Mar Sci, 2007, 64: 559-569

37 Georgakrakos S, Kitsiou D. Mapping abundance distribution of small pelagic species applying hydroacoustic and Co-kriging techniques. Hydrobiol, 2008, 612: 155-169

38 Institute of Hydrobiology. The Yangtze Fish Species (in Chinese). Beijing: Sciences Press, 1976

39 Braccini J M, Etienne M P, Martell S J D. Subjective judgement in data subsetting: implications for CPUE standardisation and stock assessment of non-target chondrichthyans. Mar Freshwater Res, 2011, 62: 734-743

40 Peltonen H, Ruuhijarvi J, Malinen T, et al. Estimation of roach (Rutilus rutilus L.) and smelt (Osmerus eperlanus L.) stocks with virtual population analysis, hydroacoustics and gillnet CPUE. Fish Res, 1999, 44: 25-36
41 Chang J, Duan Z, Qiao Y, et al. Technical report of surveying station of endangered fishes and fisheries in the Yangtze River (1996-2003) (in Chinese). Institute of Hydrobiology, Chinese Academy of Sciences, Wuhan, 2005

42 De Jalon D G, Sanchez P, Camargo J A. Downstream effects of a new hydropower impoundment on macrophyte, macroinvertebrate and fish communities. Regul Rivers: Res Mgmt, 1994, 9: 253-261

43 Morita K, Morita S H, Yamamoto S. Effects of habitat fragmentation by damming on salmonid fishes: lessons from white-spotted charr in Japan. Ecol Res, 2009, 24: 711-722

44 Han M, Fukushima M, Kameyama S, et al. How do dams affect freshwater fish distributions in Japan? Statistical analysis of native and nonnative species with various life histories. Ecol Res, 2008, 23: 735-743

45 García A, Jorde K, Habit E, et al. Downstream environmental effects of dam operations: Changes in habitat quality for native fish species. River Res Appl, 2011, 27: 312-327

46 Robinson C T, Uehlinger U. Experimental floods cause ecosystem regime shift in a regulated river. Ecol Appl, 2008, 18: 511-526

47 Barrella W, Petrere M. Fish community alterations due to pollution and damming in Tietê and Paranapanema rivers (Brazil). River Res Appl, 2003, 19: 59-76

48 Mallen-Cooper M. Habitat changes and declines of freshwater fish in Australia: what is the evidence and do we need more? In: Hancock D A, ed. Sustainable Fisheries through Sustaining Fish Habitat. Canberra: Australian Government Printing Service, 1993

Open Access This article is distributed under the terms of the Creative Commons Attribution License which permits any use, distribution, and reproduction in any medium, provided the original author(s) and source are credited. 